\title{
Comparing Libraries of Public Historically Black Colleges and Universities with Their White Counterparts
}

\section{Jim Gravois}

\begin{abstract}
As one element in the effort to desegregate public institutions of higher education, federal courts have mandated the upgrading of libraries at public historically Black colleges and universities. This preliminary study compares the libraries of public HBCUs with those of traditionally White public colleges across eighteen states, mostly in the Southeast. By analyzing number of volumes, staff, and salary totals, the study identifies states that have made efforts to upgrade their HBCU libraries and those that have not.
\end{abstract}

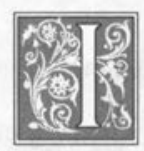

$\mathrm{n}$ the years following the 1954 ruling in Brown v. Board of Education, public colleges throughout the southern and border states opened their doors to African American students. As a result, young African Americans wishing to attend a state college now have a choice between historically Black colleges and universities (HBCUs) and the former all-White colleges and universities (non-HBCUs). However, despite the open doors of nonHBCUs, 107 HBCUs- two-year and fouryear, public and private-continue to thrive. $^{1}$

Federal courts approached racial segregation in higher education in two ways. The obvious way involved abolishing admissions policies that prohibited Blacks from enrolling at public non-HBCUs. The second mandated the upgrading of curricula, facilities, and libraries at public HBCUs to attract White students to those schools. ${ }^{2}$ Have the various states dedicated the funding needed to improve their public HBCU libraries? Would a snapshot comparison of public HBCU libraries with public non-HBCU libraries verify such improvement? This question motivated the author to undertake this preliminary investigation.

\section{Literature Review}

In a 1985 study of HBCUs by the U.S. Department of Education, Susan T. Hill explained that the libraries of public fouryear HBCUs held sixty-five volumes per student compared to sixty-two volumes

Jim Gravois is a Reference Librarian in the Microforms and Documents Department at the Ralph Brown Draughon Library at Auburn University, Alabama; e-mail: JGRAVOIS@LIB.AUBURN.EDU. The author wishes to thank Diane Thorne, Linda Thornton, and Harmon Straiton, all of Auburn University Libraries, for assistance with this article. 
for other public four-year institutions. ${ }^{3}$ Although Hill's study examined many other areas of information about HBCUs, this was the only comparison made between the libraries of HBCUs and traditionally White colleges.

In an attempt to update and broaden Hill's work on libraries of public HBCUs, this author conducted a thorough search of library literature. Although several investigators, including Jessie Smith and Robert Molyneux, have published good studies of these libraries, no one appears to have made an effort to compare the libraries of public HBCUs with their nonHBCU counterparts either generally or on a state-by-state basis. ${ }^{4}$ In addition, even though Molyneux's survey is more detailed than this one, he did not include all the public HBCUs in the country and made no comparisons at all with nonHBCUs.

\section{Methodology}

In contrast to Molyneux's 1989 study, this study aims to gather published library statistics and arrange them so that comparisons can be made between public $\mathrm{HBCU}$ libraries and public non-HBCU libraries. The first step involved identifying all the public four-year HBCUs and all the public non-HBCUs in the same states. The U.S. Department of Education provided this information. ${ }^{5}$ The author then compiled a list of thirty-eight public four-year HBCUs and 186 corresponding non-HBCUs. The study dropped West Virginia's two HBCUs because of their dwindling Black enrollment-about ten percent of the student body-perhaps indicating a successful effort by West Virginia to comply with court orders. ${ }^{6} \mathrm{~A}$ complete list of the thirty-six remaining HBCUs in this study, the degree level, and the percentage of Black students attending appears in table 1 .

The primary source of library data was Bowker's American Library Directory 1993-94. ${ }^{7}$ A quick perusal of this directory showed that many libraries failed to report all items of data. The author chose those categories of information which were most widely available: student enrollment, total number of volumes, total library salary expenditure, total library staff, and the breakdown of professional and nonprofessional staff. Staff totals include only full-time equivalent library employees. Items not reported enough in order to make valid comparisons for this study included total library budget and expenditures for new materials. Using the six categories above, the author entered the data into a PC-SAS database and manipulated the data to produce the following areas of comparison:

- volumes per student,

- salary expenditure per student,

- salary expenditure per library staff member,

- total library staff per hundred students,

- professional library staff per hundred students, and

- professional librarians as a percentage of the staff.

When a particular piece of information was not available in the American Library Directory, 1993-94, the author consulted The College Blue Book. ${ }^{8}$ Three HBCU libraries directly supplied missing data (Alabama State University, Mississippi Valley State University, and Alcorn A\&M). Finally, the author decided to use the Molyneux figures for two nonresponding HBCUs (Albany State and Central State).

\section{Results}

The study looked at 222 public four-year colleges in eighteen states, including thirty-six HBCUs and 186 non-HBCUs. The eighteen states, with number of HBCUs in parentheses, are: Alabama (2), Arkansas (1), Delaware (1), Florida (1), Georgia (3), Kentucky (1), Louisiana (3), Maryland (4), Missouri (2), Mississippi (3), North Carolina (5), Ohio (1), Oklahoma (1), Pennsylvania (2), South Carolina (1), Tennessee (1), Texas (2), and Virginia (2). 


\begin{tabular}{|c|c|c|c|}
\hline \multicolumn{4}{|c|}{$\begin{array}{c}\text { TABLE } 1 \\
\text { HBCU Colleges }\end{array}$} \\
\hline College & State & $\begin{array}{l}\text { Degree } \\
\text { Level }\end{array}$ & $\begin{array}{l}\text { Percentage } \\
\text { Black }\end{array}$ \\
\hline Alabama A \& M & $\mathrm{AL}$ & M & 79.0 \\
\hline Alabama State & $\mathrm{AL}$ & M & 98.0 \\
\hline Albany State & GA & M & 84.7 \\
\hline Alcorn State & MS & M & 94.2 \\
\hline Arkansas-Pine Bluff & $\mathrm{AR}$ & B & 81.0 \\
\hline Bowie State & MD & M & 67.2 \\
\hline Central State & $\mathrm{OH}$ & B & 88.2 \\
\hline Cheyney University & PA & M & 94.1 \\
\hline Coppin State & MD & M & 91.5 \\
\hline Delaware State & DE & M & 62.1 \\
\hline Elizabeth City State & $\mathrm{NC}$ & B & 73.7 \\
\hline Fayetteville State & $\mathrm{NC}$ & M & 62.6 \\
\hline Florida A \& M & $\mathrm{FL}$ & D & 88.4 \\
\hline Fort Valley State & GA & M & 92.8 \\
\hline Grambling State & LA & M & 94.5 \\
\hline Harris-Stowe State & MO & B & 75.3 \\
\hline Jackson State & MS & D & 94.0 \\
\hline Kentucky State & KY & M & 49.7 \\
\hline Langston University & $\mathrm{OK}$ & B & 51.3 \\
\hline Lincoln University & PA & M & 92.2 \\
\hline Lincoln University & MO & M & 25.8 \\
\hline Maryland-Eastern Shore & MD & D & 68.9 \\
\hline Mississippi Valley St. & MS & M & 99.4 \\
\hline Morgan State & MD & D & 92.8 \\
\hline Norfolk State & VA & M & 83.9 \\
\hline North Carolina Central & $\mathrm{NC}$ & D & 83.6 \\
\hline North Carolina A \& T & $\mathrm{NC}$ & M & 84.6 \\
\hline Prairie View A \& M & $\mathrm{TX}$ & M & 86.5 \\
\hline Savannah State & GA & M & 89.7 \\
\hline South Carolina State & $\mathrm{SC}$ & D & 93.6 \\
\hline Southern-Baton Rouge & LA & D & 93.9 \\
\hline Southern-New Orleans & LA & M & 93.8 \\
\hline Tennessee State & $\mathrm{TN}$ & D & 63.0 \\
\hline Texas Southern & $\mathrm{TX}$ & D & 83.0 \\
\hline Virginia State & VA & M & 90.2 \\
\hline Winston-Salem State & $\mathrm{NC}$ & B & 77.9 \\
\hline $\begin{array}{l}\text { ources: State Higher Edv } \\
3,1994 \text {. }\end{array}$ & les: 1 & Chroni & igher Educ \\
\hline
\end{tabular}




\section{General Comparisons}

This section examines the averages for all the HBCUs as a group, compared to the non- HBCUs as a group. Following Hill's approach, the first area of comparison is volumes per student. In this category, the non-HBCUs hold 66.22 books per student, slightly ahead of the HBCU average of 64.81 . (See table 2 for the figures cited in this section.)

The next two measurements examine salary. Six non-HBCUs gave no data on salaries, leaving a total of 216 libraries. Because of the inconsistency of data in the American Library Directory 1993-94, it is not possible to compare salaries paid to librarians directly. But figures for total salary expenditures by each library make it possible to calculate some indirect comparisons. The comparisons used are total salary expenditure per enrolled student and total salary expenditure per full-time equivalent library staff member. Because the Directory's total includes the salary expenses for student workers, the averages for salary per staff obtained in this study will be higher than the true average salaries paid to library staff. In this salary area, the study finds a pronounced difference between HBCUs and non-HBCUs. The two figures for nonHBCUs are $\$ 144.46$ per student and $\$ 26,625$ per staff member, compared with $\$ 128.84$ and $\$ 23,548$, respectively, for HBCUs.
The next three comparisons examine staffing. Are HBCU libraries able to hire staff at an equitable level with non-HBCU libraries? Because staffing data were lacking for one of the non-HBCUs, there are only 221 colleges in this set. In the first measurement, staff per student, the average for non-HBCUs is .544 and for HBCUs it is .547 staff per hundred students.

The second staff measurement is professional librarians per student. The nonHBCUs have 196 professionals per hundred students, compared to .226 for the HBCUs.

The last measurement in this staffing category is professional librarians as a percentage of the staff. Here the HBCUs seem to have an advantage. Professionals make up only 36.0 percent at nonHBCUs, while the HBCUs have 41.2 percent of their staff as professional librarians.

\section{Comparisons by Degree Level}

Because it is reasonable to expect a doctorate-granting institution to have a library larger or more extensive than one at an institution that does not grant doctoral degrees, the author has broken down his analysis to compare the libraries of like institutions. Among the 222 colleges in this study, twelve non-HBCUs and six HBCUs grant the bachelor's degree as their highest degree; ninety-one non-HBCUs and twenty-one HBCUs

grant the master's degree; eighty-three non-HBCUs and nine HBCUs grant the doctoral degree. The same six measurements will be used to compare nonHBCUs to HBCUs, only this time by highest degree offered. For the numeric comparisons, the reader should consult table 3 . 
As evident in table 3, the $\mathrm{HBCU}$ and non-HBCU doctorate-granting schools are just about even in volumes per student. Conversely, in both the bachelor's and master's degree colleges, the HBCUs have more books per student than do the non-HBCUs.

The next two areas of comparison by degree level relate to library salary expenditures. Table 3 indicates that non-HBCU doctorate-granting institutions far outpace their HBCU counterparts in the measure of library salary expenditure per student. However, the HBCUs have a higher salary at the master and bachelor levels.

The following comparison, salary expenditures per library staff member, tells a different story. As might be expected from the last measurement, there is a higher dollar total for the non-HBCU doctorate-granting institutions. But at the bachelor's and master's levels, where HBCUs have a higher salary figure per student, the HBCUs fail to keep pace. Table 3 reveals a higher dollar figure at the non-HBCU bachelor's level and a slight advantage at the non-HBCU master's level. All three levels show lower totals for the HBCUs in salary per staff.

The next three comparisons involve library staffing levels. In considering the number of library staff members per hundred students, table 3 shows that the nonHBCUs at the doctoral level have higher staff numbers compared to doctorategranting HBCUs. However, HBCUs have higher staff numbers at the bachelor and master levels than do similar nonHBCUs.

When looking at comparisons of professional librarians per hundred students, the HBCUs show consistently better numbers. At all three degree levels, the HBCUs have a greater proportion of professional librarians per student (see table 3 ).

The third staff comparison relates to the measure of professional librarians as a percentage of the total library staff. Here again, table 3 demonstrates that HBCUs outpace non-HBCUs at all three levels.

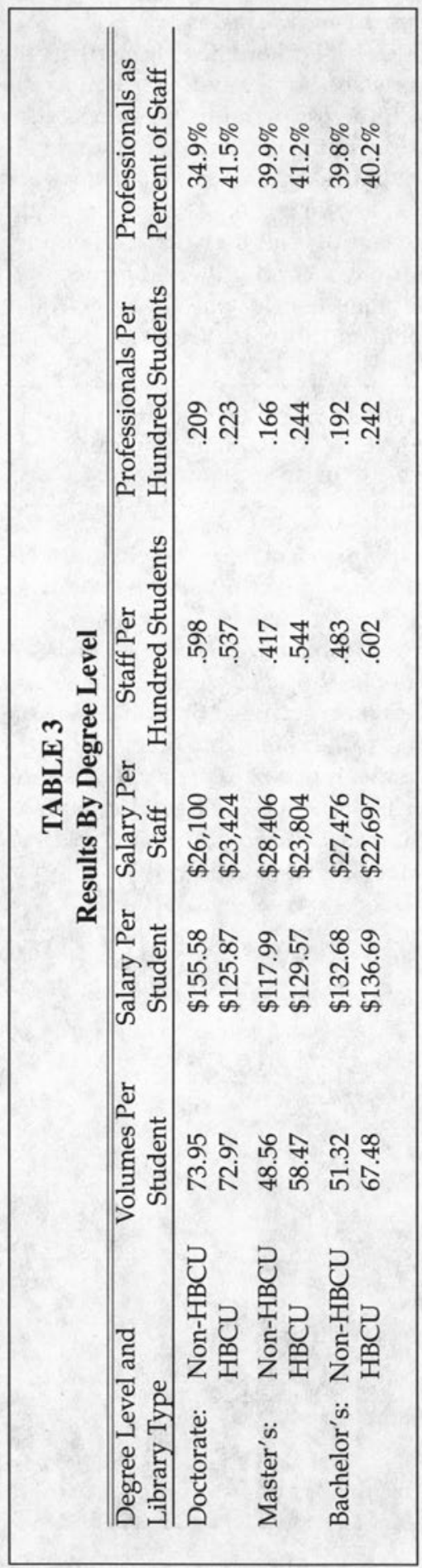




\section{Comparisons by State}

Although it is informative to compare the libraries of HBCUs with those of nonHBCUs across the eighteen state totals, it is far more important to measure the totals within each state. After all, the courts aimed to promote equal access to higher education within each state. Therefore, this final section allows the reader to draw some conclusions about the equality or inequality of public academic librar-

... HBCUs have higher staff numbers at the bachelor and master levels than do similar non-HBCUs.

ies within each of the eighteen states. The reader should consult table 4 and the six figures to follow this discussion.

The first measure of comparison is volumes per student. A glance at figure 1 makes it obvious that three states-Kentucky, Oklahoma, and Pennsylvaniahave greater book totals per student for their HBCUs than for their non-HBCUs. An analysis of the numbers in table 4 indicates that Arkansas, Delaware, Florida,
Georgia, Louisiana, Maryland, and Texas also total greater scores for their HBCUs. Mississippi shows a virtual tie, but the remaining states-Alabama, Missouri, North Carolina, Ohio, South Carolina, Tennessee, and Virginia-all show totals indicating a sizable advantage for the non-HBCUs. The greatest disparities occur in Pennsylvania and Ohio. In Pennsylvania, the two HBCUs average 138.39 books per student, compared to 69.62 books for the seventeen non-HBCUs. Conversely, in Ohio the single HBCU has only 36.88 volumes per student, while the twelve non-HBCUs average 76.97 books.

The next two comparisons examine salary: total library expenditure per student and total library expenditure per library staff member. A cursory inspection of figure 2 shows that HBCUs have much higher salary-per-student totals than the non-HBCUs in Delaware, Kentucky, Maryland, Mississippi, Oklahoma, and Pennsylvania. A closer review of the numbers in table 4 indicates that Arkansas also has a much higher salary per student at its single $\mathrm{HBCU}$ than at its eight nonHBCUs, and that Alabama has no notable

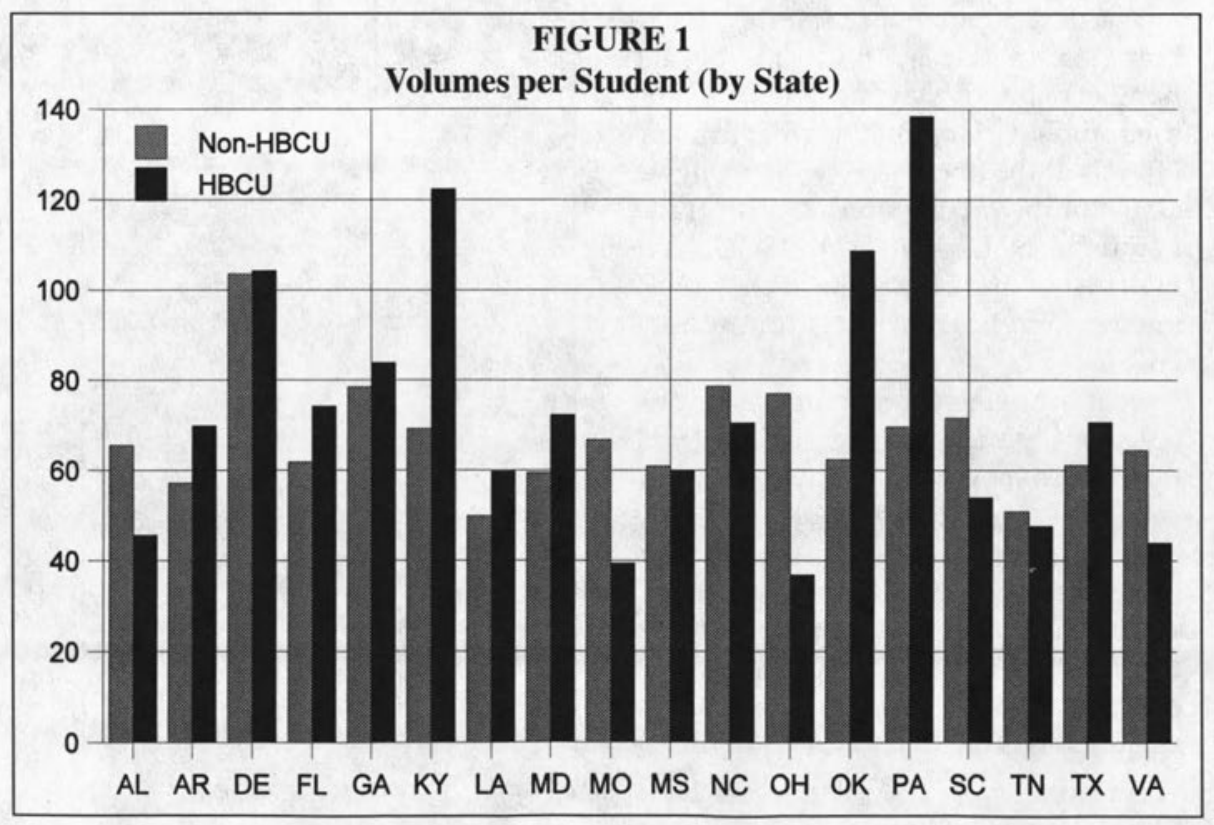




\section{TABLE 4}

Results by State

\begin{tabular}{|c|c|c|c|c|c|c|}
\hline $\begin{array}{c}\text { State and } \\
\text { Type of College }\end{array}$ & $\begin{array}{c}\text { Volumes Per } \\
\text { Student }\end{array}$ & $\begin{array}{l}\text { Salary Per } \\
\text { Student }\end{array}$ & $\begin{array}{c}\text { Salary Per } \\
\text { Staff }\end{array}$ & $\begin{array}{c}\text { Staff Per } \\
\text { Hundred Students } \\
\end{array}$ & $\begin{array}{l}\text { Professionals Per } \\
\text { Hundred Students }\end{array}$ & $\begin{array}{l}\text { Professionals as } \\
\text { Percent of Staff }\end{array}$ \\
\hline AL Non-HBCU & 65.55 & $\$ 118.60$ & $\$ 25,120$ & .472 & .190 & $40.3 \%$ \\
\hline AL $\mathrm{HBCU}$ & 45.65 & $\$ 112.84$ & $\$ 22,369$ & .504 & .202 & $40.0 \%$ \\
\hline AR Non-HBCU & 57.20 & $\$ 112.49$ & $\$ 24,910$ & .452 & .165 & $36.7 \%$ \\
\hline AR HBCU & 69.86 & $\$ 129.12$ & $\$ 17,935$ & .720 & .239 & $33.3 \%$ \\
\hline DE Non-HBCU & 103.52 & $\$ 216.65$ & $\$ 27,081$ & .800 & .255 & $31.9 \%$ \\
\hline DE HBCU & 104.28 & $\$ 285.19$ & $\$ 31,998$ & .891 & .401 & $45.0 \%$ \\
\hline FL Non-HBCU & 61.84 & $\$ 163.70$ & $\$ 27,728$ & .590 & .223 & $37.8 \%$ \\
\hline FL $\mathrm{HBCU}$ & 74.17 & $\$ 147.00$ & $\$ 24,501$ & .600 & .233 & $38.9 \%$ \\
\hline GA Non-HBCU & 78.46 & $\$ 151.20$ & $\$ 24,417$ & .619 & .217 & $35.0 \%$ \\
\hline GA HBCU & 83.85 & $\$ 123.18$ & $\$ 23,742$ & .519 & .187 & $36.1 \%$ \\
\hline KY Non-HBCU & 69.22 & $\$ 173.93$ & $\$ 26,931$ & .646 & .239 & $37.0 \%$ \\
\hline KY HBCU & 122.42 & $\$ 222.88$ & $\$ 26,003$ & .857 & .381 & $44.4 \%$ \\
\hline LA Non-HBCU & 49.90 & $\$ 94.29$ & $\$ 25,965$ & .363 & .148 & $40.6 \%$ \\
\hline LA HBCU & 59.76 & $\$ 79.01$ & $\$ 20,718$ & .381 & .183 & $48.1 \%$ \\
\hline MD Non-HBCU & 59.43 & $\$ 194.62$ & $\$ 31,584$ & .616 & .235 & $38.2 \%$ \\
\hline MD HBCU & 72.31 & $\$ 229.70$ & $\$ 31,553$ & .728 & .318 & $43.7 \%$ \\
\hline MO Non-HBCU & 66.79 & $\$ 131.33$ & $\$ 27,167$ & .483 & .169 & $35.1 \%$ \\
\hline MO $\mathrm{HBCU}$ & 39.38 & $\$ 87.18$ & $\$ 23,082$ & .378 & .189 & $50.0 \%$ \\
\hline MS Non-HBCU & 60.95 & $\$ 111.07$ & $\$ 21,296$ & .522 & .221 & $42.5 \%$ \\
\hline MS HBCU & 60.06 & $\$ 144.61$ & $\$ 23,305$ & .621 & .230 & $37.1 \%$ \\
\hline NC Non-HBCU & 78.60 & $\$ 194.78$ & $\$ 25,695$ & .758 & .258 & $34.1 \%$ \\
\hline NC $\mathrm{HBCU}$ & 70.47 & $\$ 149.58$ & $\$ 21,478$ & .696 & .313 & $45.0 \%$ \\
\hline OH Non-HBCU & 76.97 & $\$ 162.06$ & $\$ 29,285$ & .553 & .206 & $37.3 \%$ \\
\hline $\mathrm{OH} \mathrm{HBCU}$ & 36.88 & $\$ 112.63$ & $\$ 27,942$ & .403 & .147 & $36.4 \%$ \\
\hline OK Non-HBCU & 62.38 & $\$ 94.74$ & $\$ 26,301$ & .441 & .174 & $39.4 \%$ \\
\hline $\mathrm{OK} \mathrm{HBCU}$ & 108.66 & $\$ 132.60$ & $\$ 24,000$ & .552 & .184 & $33.3 \%$ \\
\hline PA Non-HBCU & 69.62 & $\$ 189.76$ & $\$ 35,147$ & .535 & .202 & $37.8 \%$ \\
\hline PA HBCU & 138.39 & $\$ 247.65$ & $\$ 28,242$ & .877 & .386 & $44.0 \%$ \\
\hline SC Non-HBCU & 71.58 & $\$ 137.82$ & $\$ 26,918$ & .512 & .190 & $37.2 \%$ \\
\hline SC $\mathrm{HBCU}$ & 53.96 & $\$ 85.52$ & $\$ 23,643$ & .362 & .191 & $52.9 \%$ \\
\hline TN Non-HBCU & 50.85 & $\$ 113.27$ & $\$ 22,414$ & .505 & .170 & $33.7 \%$ \\
\hline TN HBCU & 47.60 & $\$ 102.41$ & $\$ 19,004$ & .539 & .229 & $42.5 \%$ \\
\hline TX Non-HBCU & 61.11 & $\$ 108.02$ & $\$ 22,207$ & .488 & .158 & $32.4 \%$ \\
\hline TX HBCU & 70.62 & $\$ 93.92$ & $\$ 20,489$ & .458 & .148 & $32.4 \%$ \\
\hline VA Non-HBCU & 64.44 & $\$ 168.37$ & $\$ 26,019$ & .647 & .218 & $33.6 \%$ \\
\hline VA HBCU & 43.93 & $\$ 98.50$ & $\$ 22,688$ & .434 & .150 & $34.6 \%$ \\
\hline
\end{tabular}

difference between the two. By this measure, however, all of the other ten states have a higher salary per student at their non-HBCUs. The greatest margins of difference are found in Oklahoma and Virginia. Oklahoma's single HBCU has an average salary per student of $\$ 132.60$, compared to $\$ 94.74$ for its six nonHBCUs. Conversely, Virginia has an average of $\$ 168.37$ for its thirteen nonHBCUs, compared to only $\$ 98.50$ for its two HBCUs.

The next category is salary per staff member. Figure 3 suggests there might be 


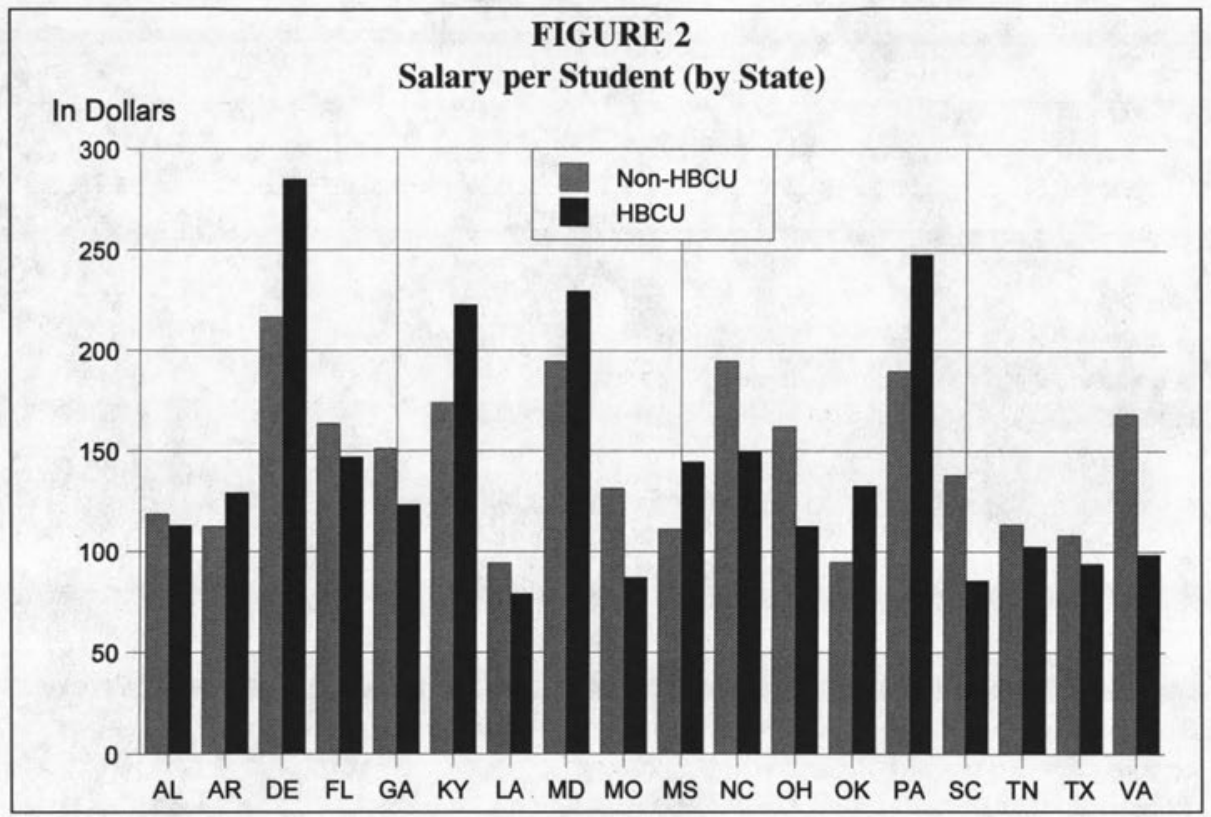

more equity in the eighteen states by this measurement, because only two or three states show obvious differences at first glance. An analysis of the numbers in table 4, however, indicates that only two states, Delaware and Mississippi, have higher salaries per staff member at their HBCUs. Four states-Georgia, Kentucky, Maryland, and Ohio-are nearly equal. That leaves twelve states that have a much higher average of salary per staff member at the non-HBCUs than at the

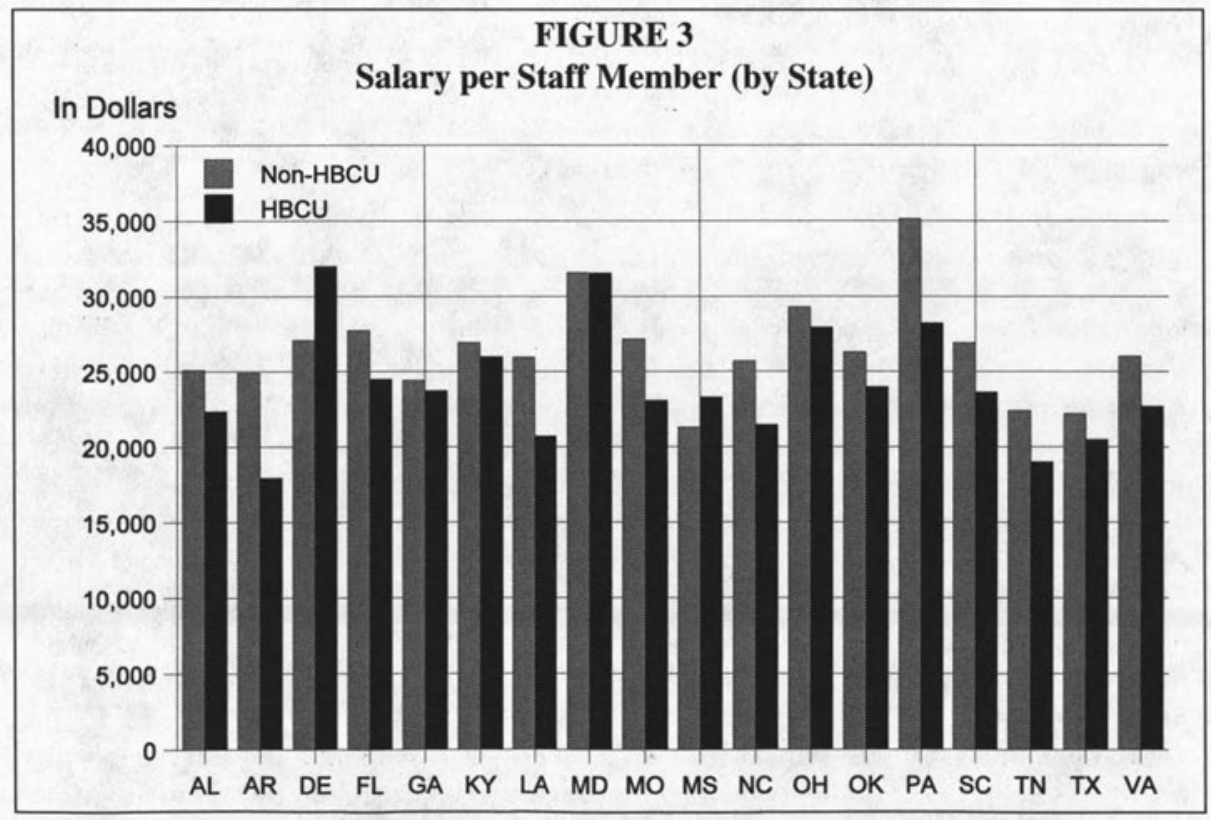




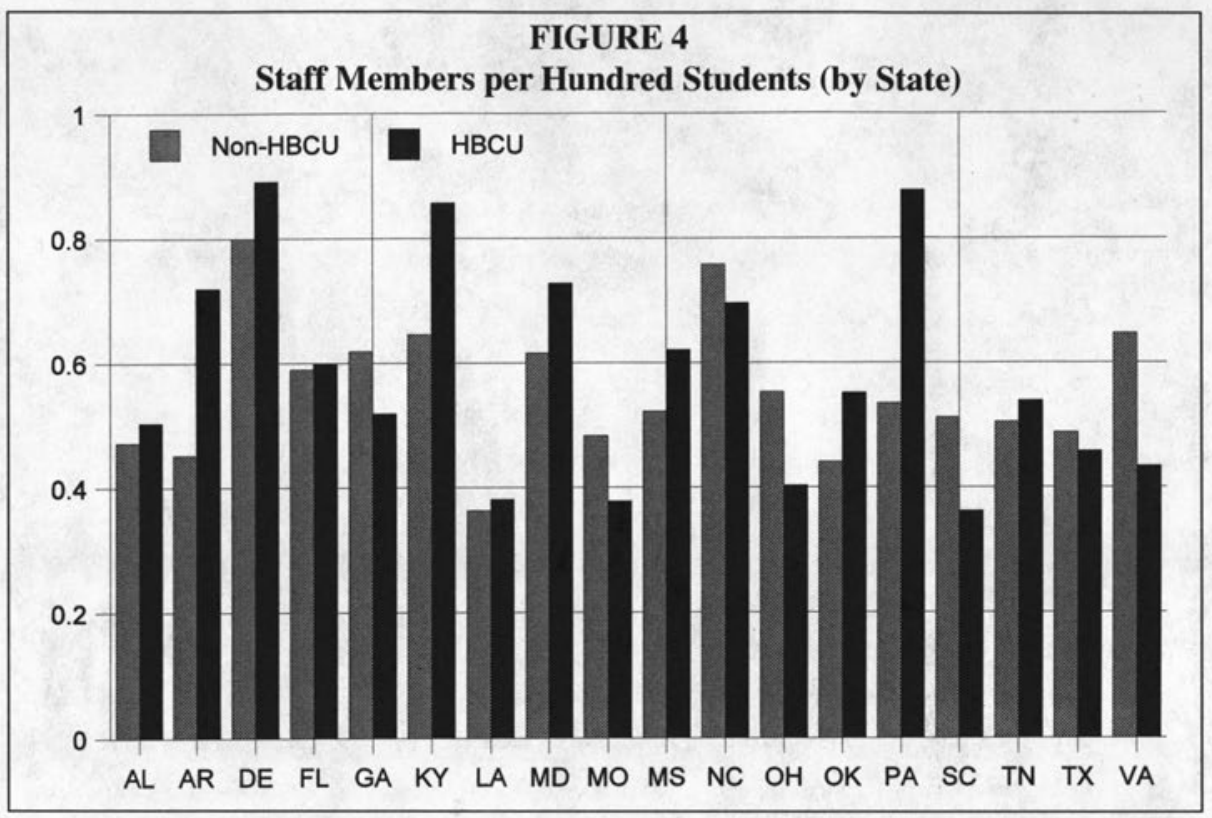

HBCUs. The greatest differences on both ends of the spectrum are in Delaware and Arkansas. Delaware's HBCU averages $\$ 31,998$ of salary per staff member, while its single non-HBCU averages only $\$ 27,081$. In Arkansas, the contrast is greater. Its eight non-HBCUs have an average salary per staff member of $\$ 24,910$, compared to only $\$ 17,935$ for its only HBCU.

The next issue concerns the size of library staffs at HBCUs and non-HBCUs. Figure 4 illustrates the comparison of fulltime equivalent staff members per hundred students. Again, certain states stand out as having a higher total of staff per student in their HBCUs. These states include Arkansas, Kentucky, and Pennsylvania. Other states that also measure more staff at their HBCUs are Alabama, Delaware, Florida, Louisiana, Maryland, Mississippi, Oklahoma, and Tennessee. However, seven states-Georgia, Missouri, North Carolina, Ohio, South Carolina, Texas, and Virginia-show better staff-to-student ratios at their nonHBCUs. The greatest disparities occur in Pennsylvania and Virginia. Pennsyl- vania's two HBCUs have .877 staff members per hundred students, compared to an average of .535 at the seventeen nonHBCUs. In Virginia, the reverse is true. Virginia's two HBCUs have only .434 staff members per hundred students, compared to .647 staff members for the thirteen non-HBCUs.

The next staffing comparison involves the number of professional librarians per hundred students. A quick glance at figure 5 shows that Arkansas, Delaware, Kentucky, Maryland, North Carolina, Pennsylvania, and Tennessee have more professional librarians per student in their HBCUs than in their non-HBCUs. Although not so obvious, Alabama, Florida, Louisiana, Mississippi, Missouri, Oklahoma, and South Carolina have a slight advantage for their HBCUs in this category (see table 4 ). The only states that measure a distinct advantage for their non-HBCUs in this category are Georgia, Ohio, Texas, and Virginia. The greatest disparities are again found in Pennsylvania and Virginia. Pennsylvania's two HBCUs have an average of .386 professional librarians per hundred students, 


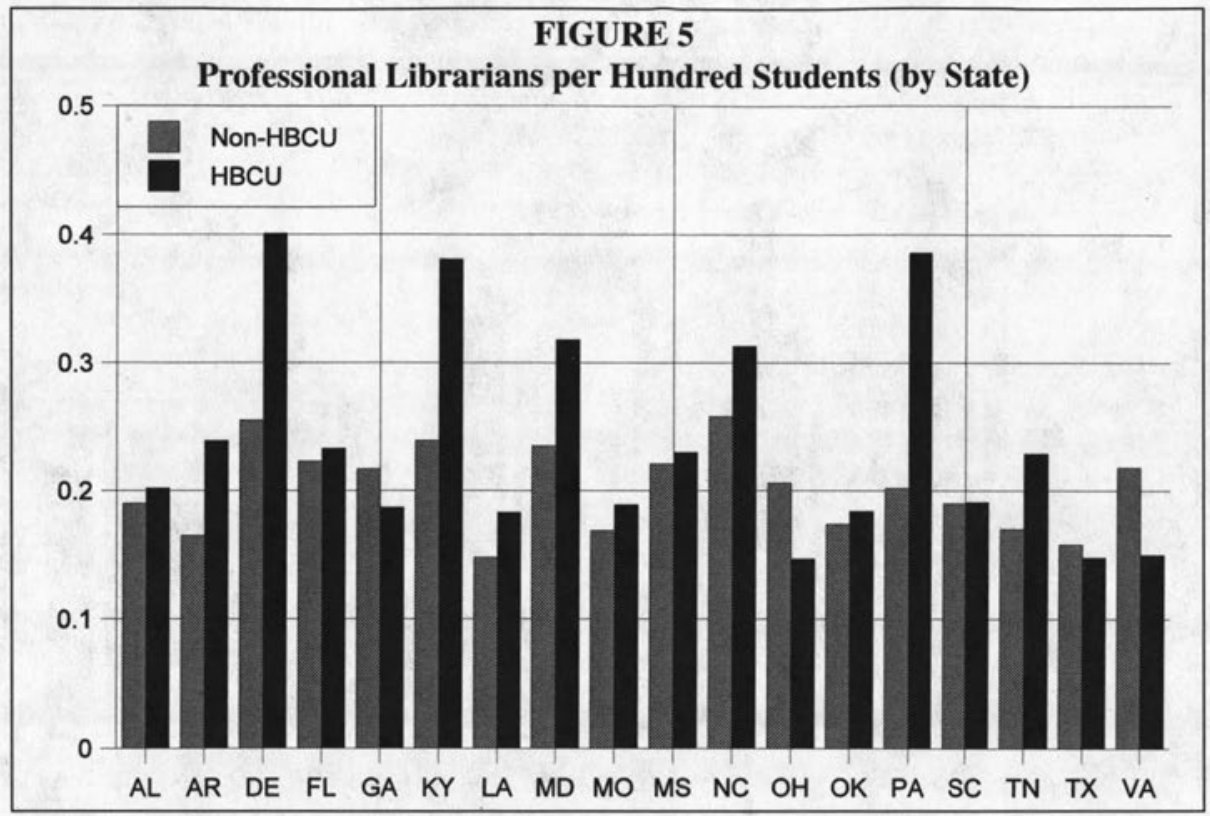

compared to .202 professionals for the seventeen non-HBCU colleges. Meanwhile, Virginia has .218 professionals in its thirteen non-HBCU colleges, compared to an average of only .150 in its two HBCUs.
The final staffing comparison is the measure of professional librarians as a percentage of the total library staff. This is the measure that shows the greatest advantage for the HBCUs, as indicated in figure 6 where the black bars seem taller

FIGURE 6

Professional Librarians as Percent of Staff (by State)

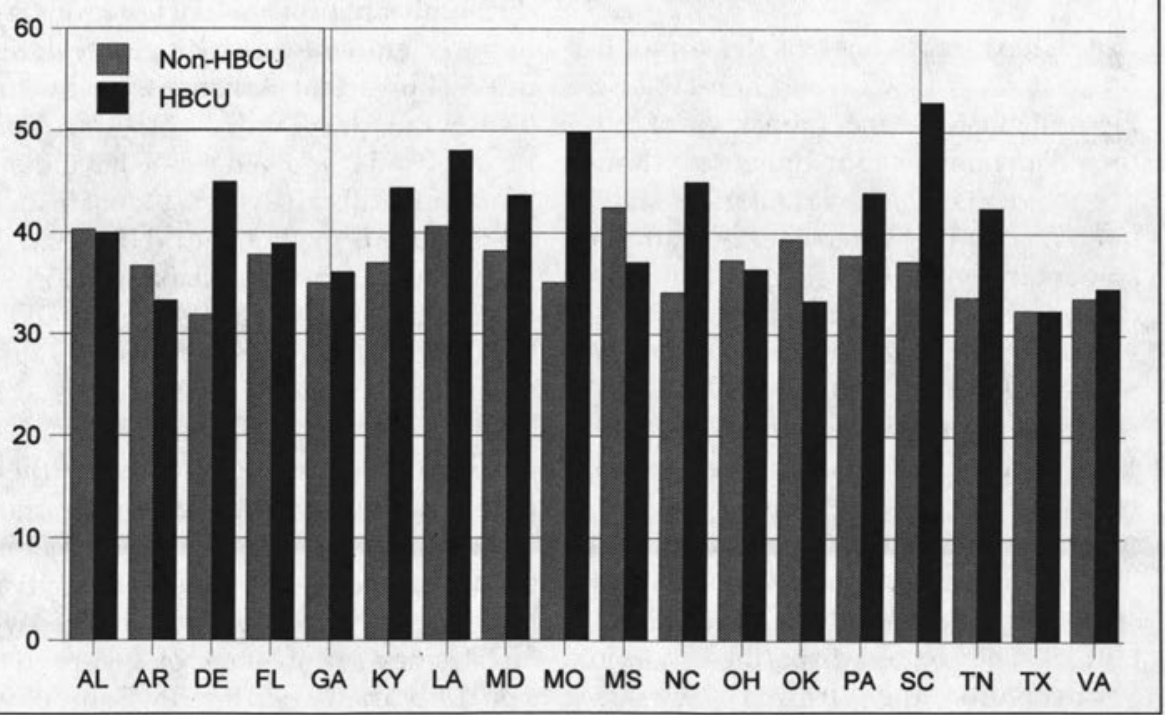


than the white in almost every state. In fact, the numbers in table 4 indicate that non-HBCUs have a greater ratio of professional librarians in only three states: Arkansas, Mississippi, and Oklahoma. Six other states-Alabama, Florida, Georgia, Ohio, Texas, and Virginia-show results within approximately one percentage point. The remaining nine states have a higher percentage of professional librarians on staff at the HBCUs. In this category, the greatest disparities occur in South Carolina and Oklahoma. South Carolina's lone $\mathrm{HBCU}$ has a percentage of 52.9 professional librarians on staff, compared to 37.2 for its ten non- HBCUs. In Oklahoma, the figures are 39.4 percent for the eight non-HBCUs and only 33.3 percent for the single $\mathrm{HBCU}$.

\section{Discussion}

In general, using the data for all the HBCUs and all the non-HBCUs, there appears to be no notable difference between HBCUs and non-HBCUs in the measurements of volumes per student, library staff per student, and professional librarians per student. However, the HBCUs have an advantage in the measure of professional librarians as a percentage of the staff, while the non-HBCUs outpace the HBCUs in salary per student and salary per staff member (see table 2).

When comparisons are broken down by degree level, the doctorate-granting institutions score higher than master's and bachelor's institutions in all measures except professionals as a percentage of the staff. In the HBCU comparisons with nonHBCUs, HBCUs equal or surpass nonHBCUs on all levels in volumes per student, professional librarians per student, and professionals as a percentage of the staff. HBCUs also score higher on the bachelor's and master's levels in the measures of staff members per student and salary per student. On the doctoral level, the non-HBCUs are ahead in these two categories. When salary per staff member is analyzed, however, the non-HBCUs are far ahead on all levels (see table 3).

At this juncture, the reader can draw some general conclusions when comparing HBCUs and non-HBCUs: the two are fairly equal in volumes per student, HBCUs are usually superior in library staffing measures, and the non-HBCUs are generally ahead in salary measurements. However, the courts are not interested so much in general averages across state lines as they are in direct comparisons between HBCUs and non-HBCUs within each state. The question remains: have the states upgraded their HBCU libraries? The earlier discussion of the data contained in figures $1-6$ and table 4 can lead the reader to some general conclusions about the states.

\section{In general, ... there appears to be no notable difference between HBCUs and non-HBCUs in measure- ments of volumes per student, library staff per student, and professional librarians per student.}

Based on the general averages, most of the states have strong scores for their HBCUs in volumes and staffing, but weak scores in salary measurements. However, the totals for certain states merit closer scrutiny. Delaware is the only state in which the HBCU library scores higher than its non-HBCU counterpart in every category (see table 4). Kentucky, Maryland, and Pennsylvania are states where HBCU libraries score higher in every category but one-salary per staff member. Interestingly, while the scores in that category are just about equal for the HBCUs and non-HBCUs of Kentucky and Maryland, non-HBCUs in Pennsylvania score much higher in salary per staff member.

The states that appear to support their non-HBCU libraries more than their HBCU libraries are Alabama, Florida, Georgia, Ohio, South Carolina, and Virginia. This conclusion is based on the fact that not one of these states produces a better result for its HBCUs in more than 
one category (see table 4). In fact, the HBCUs of Ohio and Virginia do not score better than their non-HBCUs in any of the categories, suggesting that these two states have the most work to do in bringing about equity.

\section{Conclusion}

Before pointing fingers at individual states and allowing others to rest on their laurels, it is important to emphasize the limitations of this study. The American $\mathrm{Li}$ brary Directory's data are only as accurate as the reporting libraries make them. Furthermore, no attempt was made to measure microform holdings, to examine the condition of library buildings, to analyze the progress of automation, to survey the age of book collections, or to examine interlibrary loan activity. Besides, the raw numbers tell us nothing about patron satisfaction levels, which may be the most important measure of all. Even so, despite the limitations of this study, the data presented here appear to demonstrate unequal treatment of $\mathrm{HBCU}$ libraries in several states.

In the end, this preliminary investigation has only scratched the surface and suggests many areas for further research.
Is there a correlation between library strengths and the number of non-Black students enrolled at HBCUs? For example, does Kentucky State University score well in these comparisons because its student body is less than fifty percent Black? Would an analysis of the Hispanic and/or Native American enrollment in Texas and Oklahoma cast new light on these findings?

What is the reason for the uniformly lower salary figures at HBCUs? Do these states have standardized pay grades at all public colleges? Do pay grades vary by type of institution or regional location within the states? Why do Pennsylvania's HBCUs compare so well in every category except salary per staff? Why does Ohio, another northern state, have such low numbers for its HBCU?

In sum, this author can only conclude that each state must take a closer look at the results of this study and make similar studies of its own. By doing so, states can determine what steps will be necessary to equalize or enhance the libraries of HBCUs. Other researchers, too, it is hoped, will use data generated by their local educational agencies to improve upon the results of this study.

\section{Notes}

1. Historically Black Colleges and Universities and Higher Education Desegregation (Washington, D.C.: U.S. Department of Education, Office for Civil Rights, 1991), 8.

2. Ibid., 6.

3. Susan T. Hill, The Traditionally Black Institutions of Higher Education, 1860-1982, U.S. Department of Education, National Center for Education Statistics (Washington, D.C.: U.S. Government Printing Office, 1985), 73.

4. See Jessie Carney Smith, Black Academic Libraries and Research Collections: An Historical Survey (Westport, Conn.: Greenwood Pr., 1977), and Robert Molyneux, ACRL/Historically Black Colleges and Universities Library Statistics, 1988-89 (Chicago: ACRL, 1991).

5. Charlene Hoffman, Thomas D. Snyder, and Bill Sonnenberg, Historically Black Colleges and Universities, 1976-90, U.S. Department of Education, National Center for Education Statistics (Washington, D.C.: U.S. Government Printing Office, 1992); Samuel F. Barbett, Roslyn Korb, MacKnight Black, and Martha Collins, State Higher Education Profiles, 4th ed., U.S. Department of Education, National Center for Education Statistics (Washington, D.C.: U.S. Government Printing Office, 1992).

6. "1992 Enrollment by Race at 3,300 Institutions of Higher Education," Chronicle of Higher Education 40 (Feb. 23, 1994): 31-40.

7. American Library Directory: A Classified List of Libraries in the United States and Canada, with Personnel and Statistical Data 1993-94 (New York: R. R. Bowker, 1993).

8. The College Blue Book (New York: Macmillan Information, 1993). 